\title{
Lying (non-)parents: \\ Being a parent does not reduce dishonesty
}

\author{
Agne Kajackaite* and Paweł Niszczota*
}

August 19, 2021

\begin{abstract}
Many studies point to how parenthood can affect behavior. Here, we provide a largesample $(N=2,008)$ analysis of whether people with children are less likely to cheat in a private die-rolling task. Our findings suggest that both parents and non-parents lie and do so to a similar extent. However, when parents are reminded of their children prior to the task, they lie less compared to a treatment without a reminder.
\end{abstract}

Keywords: cheating; dishonesty; lying; die-rolling paradigm; parenthood; experiment JEL classification: C90, D82, D91.

* Equal contributions. Kajackaite: WZB Berlin Social Science Center, Berlin, D-10785, Germany (email: agne.kajackaite@wzb.eu); Niszczota: Poznań University of Economics and Business, 61-875, Poland (email: pawel.niszczota@ue.poznan.pl). 


\section{Introduction}

There are many situations in everyday life and in the marketplace, in which people have an opportunity to misreport their private information for their own benefit. For instance, employees can misreport the yearly income when filing their taxes or over-report the number of hours they worked and therewith receive a larger paycheck. Politicians can lie in their campaigns to get more votes, and public officials can get involved in corrupt behaviors for monetary benefits. The economic consequences of cheating are large, and maintaining honesty is crucial for functioning of societies (e.g., Mauro, 1995). In order to prevent people from lying, it is important to understand which factors influence the decision to lie.

From a standard economic perspective, the decision to lie for a monetary benefit is affected by only two factors - the probability of being caught and the penalty resulting from it (see Becker, 1968). However, the fast-growing literature in behavioral economics shows that many people would forego an opportunity to lie, even if there is no possibility of being caught and being punished (see, for instance, Gneezy (2005), Mazar et al. (2008), Shalvi et al. (2011), Fischbacher and Föllmi-Heusi (2013), Abeler et al. (2014), Gächter and Schulz (2016), Kajackaite and Gneezy (2017), Gneezy et al. (2018), Abeler et al. (2019)). These studies show that some people lie only partially (i.e., over-report, but do not claim the maximal possible payoff) or do not lie at all, because they have an intrinsic cost of lying (a self-image cost) and/or because they do not want to be perceived as liars by others (a social image cost).

Many experimental studies have aimed at identifying further factors which affect the decision to lie (see Jacobsen et al. (2018) for a review). The experiments have shown that, for example, women are less likely to be dishonest than men (Dreber and Johannesson, 2008; Capraro, 2018), higher monetary incentives do not lead to more cheating (Kajackaite and Gneezy, 2017; Abeler et al., 2019), being reminded of a selfish identity makes one cheat more 
(Cohn et al., 2014, 2015), and being reminded of a social norm of telling the truth can make one cheat less (Boonmanunt et al., 2020). In this paper, we aim at uncovering how being a parent influences one's decision to lie. In particular, we ask: Do parents lie less than nonparents?

A number of observational studies in economics show that being a parent affects decision making. For instance, Dahl et al. (2012) find that after fathering a child, male CEOs pay their employees less generously and pay themselves more, especially after fathering a son, whereas other studies find rather positive effects on behavior, after becoming a parent. A number of studies find that men with daughters adopt more feminist views and help ensure greater gender diversity in corporate boards or venture capital teams, since they hire more women (Warner, 1991, Washington, 2008, Dasgupta et al., 2018, Calder-Wang and Gompers, 2021). Furthermore, parenting daughters increases corporate social responsibility of CEOs (Cronqvist and $\mathrm{Yu}, 2017)$.

There are also a few experimental studies examining how having a child affects preferences. Pogrebna et al. (2018) conduct a risk-taking experiment, and find that both mothers and fathers become significantly more risk-averse after finding out that they will have a daughter, whereas risk-aversion does not increase after finding out they will have a son. Niszczota and Białek (2020) find that having a daughter lowers the propensity to invest in socially controversial companies, but only for men. They find that having a daughter, however, does not reduce the propensity to work for such companies. Houser et al. (2016) study cheating behavior of parents. They find that parents cheat less when they are observed by their child, with the effect being more pronounced when the observer is a daughter than when the observer is a son.

In this study, we study lying behavior of both parents and non-parents. We use an anonymous one-shot random-draw game (similar to Fischbacher and Föllmi-Heusi (2013)), in 
which over 2,000 participants are asked to throw two dice and report the numbers that came up, with a double-six paying a bonus and other combinations resulting in no bonus. We expect that participants will cheat less when they have a daughter and/or a son than participants without children. We hypothesize that being a parent leads to higher psychological costs of lying on both self-image ("I am a dishonest parent" compared to "I am a dishonest person") and social-image domains ("They see me as a dishonest parent" compared to "They see me as a dishonest person"). Furthermore, parents are partially responsible for the development of the morality of their children (see Smetana, 1999), which, even in an anonymous situation, might stop the parents from lying.

We conduct an online experiment with two treatments. In the "Neutral" treatment, participants first participate in the random draw task, and then fill in a demographic questionnaire with an extensive questionnaire about their children. In the "Parent-Identity" treatment, participants first fill in the questionnaire, and only then participate in the random draw task. We hypothesize that parenting will have a stronger negative effect on cheating in "Parent-Identity" than in "Neutral", because we remind the parents of their parents' identity beforehand and therewith activate their parents' mindset (similarly to other cheating studies with priming, e.g., Cohn et al. (2014, 2015)).

In contrast to our hypothesis that parents will cheat less than non-parents, we find no significant differences in cheating behavior between parents and non-parents, neither in the "Neutral" nor in the "Parent-Identity" treatment. However, we find, that once we remind the parents of their parents' identity, they cheat less than when there is no reminder. That is, parenthood affects the propensity to cheat, but only when the parents' identity is activated. 


\section{Experimental design and procedure}

We use a between-subjects design with two treatments. Both treatments involve the generation of two random numbers between 1 and 6 using a roll of two dice. After observing the random outcome, participants report it and are paid a bonus if they report two sixes, and zero otherwise. In the treatments, we vary the timing of the demographic questionnaire, which is conducted either before or after the die rolling task. We pre-registered the experimental design and the hypotheses at AsPredicted. ${ }^{1}$

\section{Treatments}

Treatment 1: "Neutral." The participant anonymously rolls two six-sided dice and is then asked to report the number. If the participant reports two sixes, she receives a bonus of 0.70 GBP, and zero otherwise. In the die-rolling game, we do not know which individuals cheated and by how much, but we follow the convention in this literature and estimate the level of cheating by comparing the expected fraction of two sixes occurring, which is $1 / 36$, with the reported fraction of two sixes. After the die rolling task, the participants are asked to fill in a demographic questionnaire, which has an extensive list of questions on the participants' children (see the Appendix for the exact questionnaire).

Treatment 2: "Parent-Identity." This treatment differs from the "Neutral" treatment only by the order of the experimental game and the questionnaire. Here, the questionnaire takes place before the dice-rolling task. We do so to remind the participants who are parents of their parents' identity and increase their psychological cost of lying.

\footnotetext{
${ }^{1}$ The study was preregistered at https://aspredicted.org/LLQ_K29 and https://aspredicted.org/1RC_NY2. We first conducted the „Neutral” treatment. The „Parent-Identity” treatment was not planned at first; we decided to run it after conducting the „Neutral” treatment.
} 


\section{Experimental Procedure}

We conducted the experiment in July 2021 on Prolific (Palan and Schitter, 2018). We recruited 2,008 participants $^{2}$ (50.80\% parent; $48.71 \%$ female, $49.80 \%$ male, and $1.49 \%$ other), who were residents of the United States, had a US nationality and an approval rate of at least 95\%; none of them participated in more than one session.

Participants were paid a participation fee of 0.30 GBP (approximately 0.43 USD). During the study, they were told that they will receive a bonus of 0.70 GBP (approximately 1.00 USD) if they will report to have rolled two sixes on two six-sided dice, and zero otherwise. Participants could either use their own dice or roll the dice online at: https://www.random.org/dice/?num=2.

An experimental session lasted approximately 3 minutes, and the average pay amounted to $0.43 \mathrm{GBP}$.

\section{Hypotheses}

We expect that the psychological cost of lying increases when one becomes a parent. We hypothesize that parents have higher psychological lying costs on both self-image and social-image domains. Our intuition is that seeing yourself as a dishonest parent is costlier than seeing yourself as a dishonest person. Also, we expect that there is a higher stigma to be seen as a dishonest parent than as a dishonest person. Furthermore, parents carry a responsibility for the development of the morality of their children (see Smetana (1999)), which, we believe, even in an anonymous situation, might stop parents from lying.

\footnotetext{
2 We aimed to have 2,000 participants, in order to have 250 participants in each of these sub-groups: TR1parent-male, TR1-parent-female, TR1-non-parent-male, TR1-non-parent-female, TR2-parent-male, TR2-parentfemale, TR2-non-parent-male, and TR2-non-parent-female. Our sample size gave us 97\% power to detect a 5percentage point difference in cheating behavior, with $20 \%$ serving as a baseline reporting of two sixes.
} 
Hypothesis 1. (Over-reporting and parenthood): The fraction of two sixes reported will be smaller for parents than non-parents:

$$
\text { Two Sixes (Parents) < Two Sixes (Non-Parents) }
$$

However, it could be that some participants in the treatment "Neutral" do not think about their parent identity when participating in the dice-rolling task. Experiments by Cohn et al. $(2014,2015)$ have shown that bankers and prisoners cheat more when they are reminded of their criminal (prisoners) or professional (bankers) identity. We expect, therefore, that parents will cheat less in the "Parent-Identity" treatment than in the "Neutral" treatment, because we remind them of their parenthood just before the dice-rolling task.

Hypothesis 2. (Over-reporting and priming): The fraction of two sixes reported will be smaller for parents, when they are reminded of their parent's identity:

Two Sixes (Parents in "Parent-Identity") < Two Sixes (Parents in "Non-Parents")

We expect no priming effect for non-parents, because the only question they are asked about children is whether they have them. Parents, on the other hand, have to fill in an extensive questionnaire on their children.

\section{Results}

If the participants were honest, $2.78 \%$ (1/36) of them would report that they rolled two sixes. In our experiment, however, $19.12 \%$ of participants reported two-sixes, which is 
substantially different from what we would observe in an entirely-honest sample $(p<0.001$, binomial test). ${ }^{3}$

In the next step, we test whether parents lie less often than non-parents. When looking at the data in both treatments together, we find that $19.33 \%$ of non-parents and $18.92 \%$ of parents report two sixes. Even though parents lie slightly less often, this difference is not substantial and far from statistical significance ( $p=0.815$, Chi-squared test).

Figure 1 displays reporting of two sixes in "Neutral" and "Parent-Identity" treatments. In the "Neutral" treatment, non-parents and parents report two sixes in $19.40 \%$ and $21.34 \%$ of the cases, respectively. That is, parents even cheat slightly more often than non-parents, but the difference is not statistically significant $(p=0.444$, Chi-squared test). In the "ParentIdentity" treatment, non-parents and parents report two sixes in $19.26 \%$ and $16.54 \%$ of the cases, respectively. Thus, in this treatment, parents cheat less often than non-parents, but the effect is again not statistically significant ( $p=0.260$, Chi-squared test).

Thus, given the aggregate lying rates and the lying rates in each treatment separately, we find no support for Hypothesis 1, and therefore reject the Hypothesis.

Result 1. Parents and non-parents cheat and do so to a similar extent.

In the next step, we test Hypothesis 2. For this purpose, we consider only the parents and compare their reporting of two sixes between the treatments. When the parents are reminded of their parents' identity, reporting of two sixes decreases by 4.8 percentage points (21.34\% in "Neutral" vs. $16.54 \%$ in "Parent-Identity"). This difference is significant at the 5\% level ( $p=0.050$, Chi-squared test). Thus, we find support for Hypothesis 2. However, note

\footnotetext{
${ }^{3}$ All tests in this paper are two-sided.
} 
that the effect is not substantial. Furthermore, as expected, the priming has no effect on nonparents (19.40\% in "Neutral vs. $19.26 \%$ in "Parent-Identity"; $p=0.956$, Chi-squared test).

Result 2. Parents lie less when they are reminded of their parents' identity, compared to the no-reminder (neutral) condition.

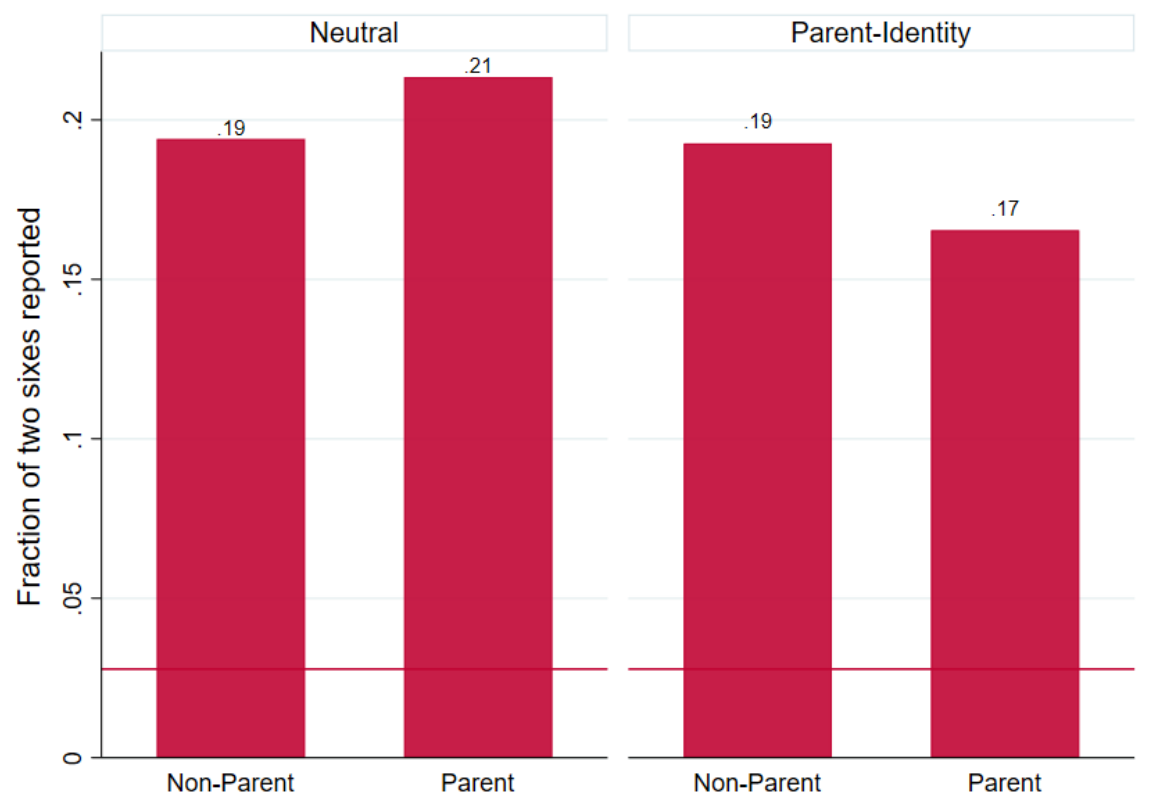

Fig. 1. Fraction of reported two sixes

Note: The horizontal line highlights the expected fraction of two sixes reported if the participants are truthful. The number of observations amounts to 500, 506, 488, and 514 in Neutral-Non-Parent, Neutral-Parent, Parent-Identity-Non-Parent, and Parent-Identity-Parent, respectively.

\section{Gender}

We find that men lie significantly more often than women (reporting two sixes in $23.80 \%$ and $14.31 \%$ of the cases respectively; $p<0.001$, Chi-squared test), which is in line with the gender effects found in the lying literature (see Abeler et al. (2019)). ${ }^{4}$ In line with the

\footnotetext{
${ }^{4}$ There were 30 people in the experiment, who identified their gender as "other". In this gender group, $20 \%$ reported two sixes.
} 
aggregate results, being a parent does not make neither men $(23.01 \%$ and $24.56 \%$ for nonparents and parents, respectively; $p=0.567$, Chi-squared test $)$ nor women $(15.50 \%$ and $13.21 \%$ for non-parents and parents, respectively; $p=0.308$, Chi-squared test) lie less.

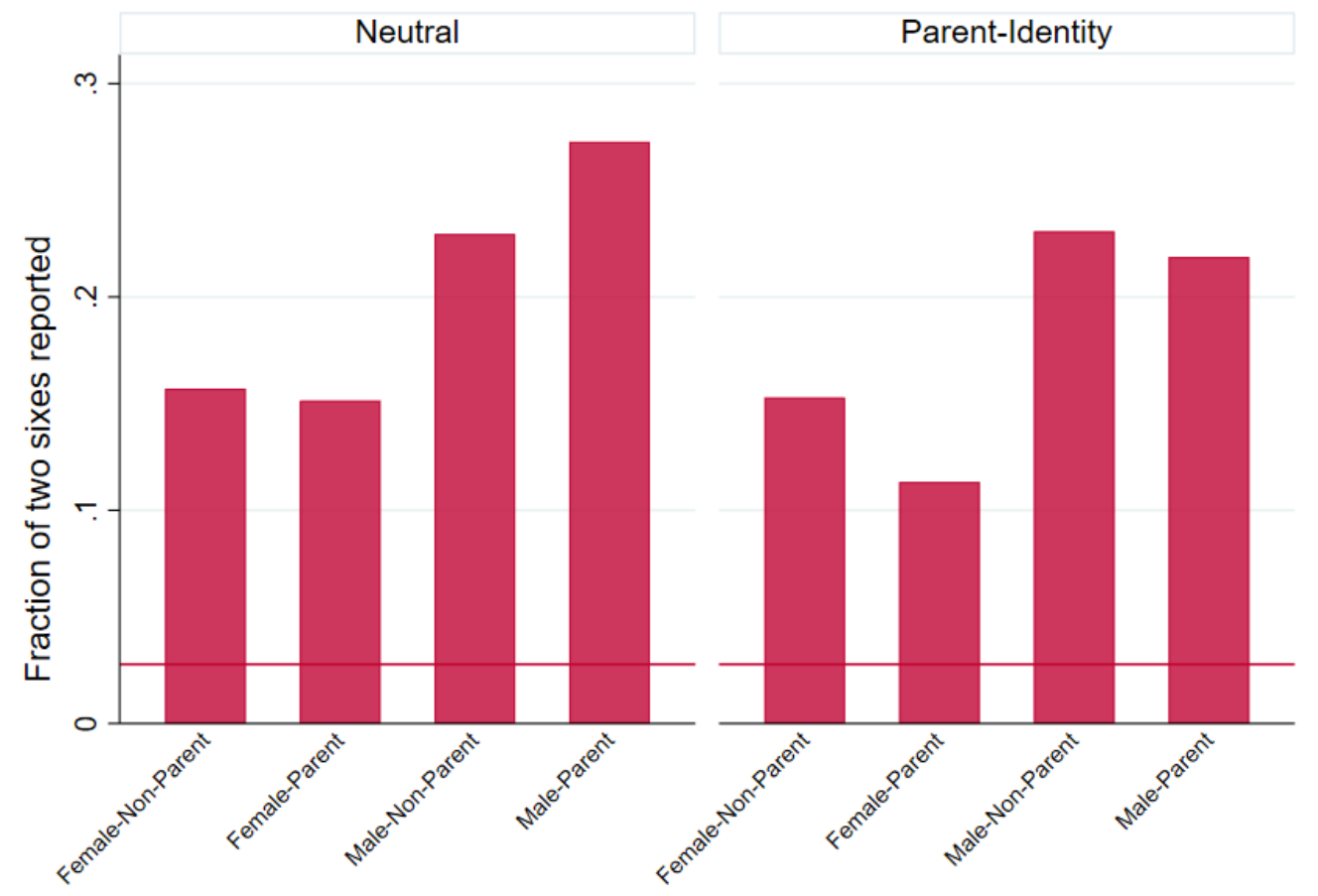

Fig. 2. Fraction of reported two sixes by gender

Note: The horizontal line highlights the expected fraction of two sixes reported, if the participants are truthful.

Figure 2 displays reporting of two sixes in "Neutral" and "Parent-Identity" treatments, by gender. While this figure displays strong gender differences in reporting, there are no treatment effects for neither men nor women. All comparisons of reporting of two sixes between parents and non-parents or between experimental treatments lead to $p>0.1$ in a Chisquared test. 


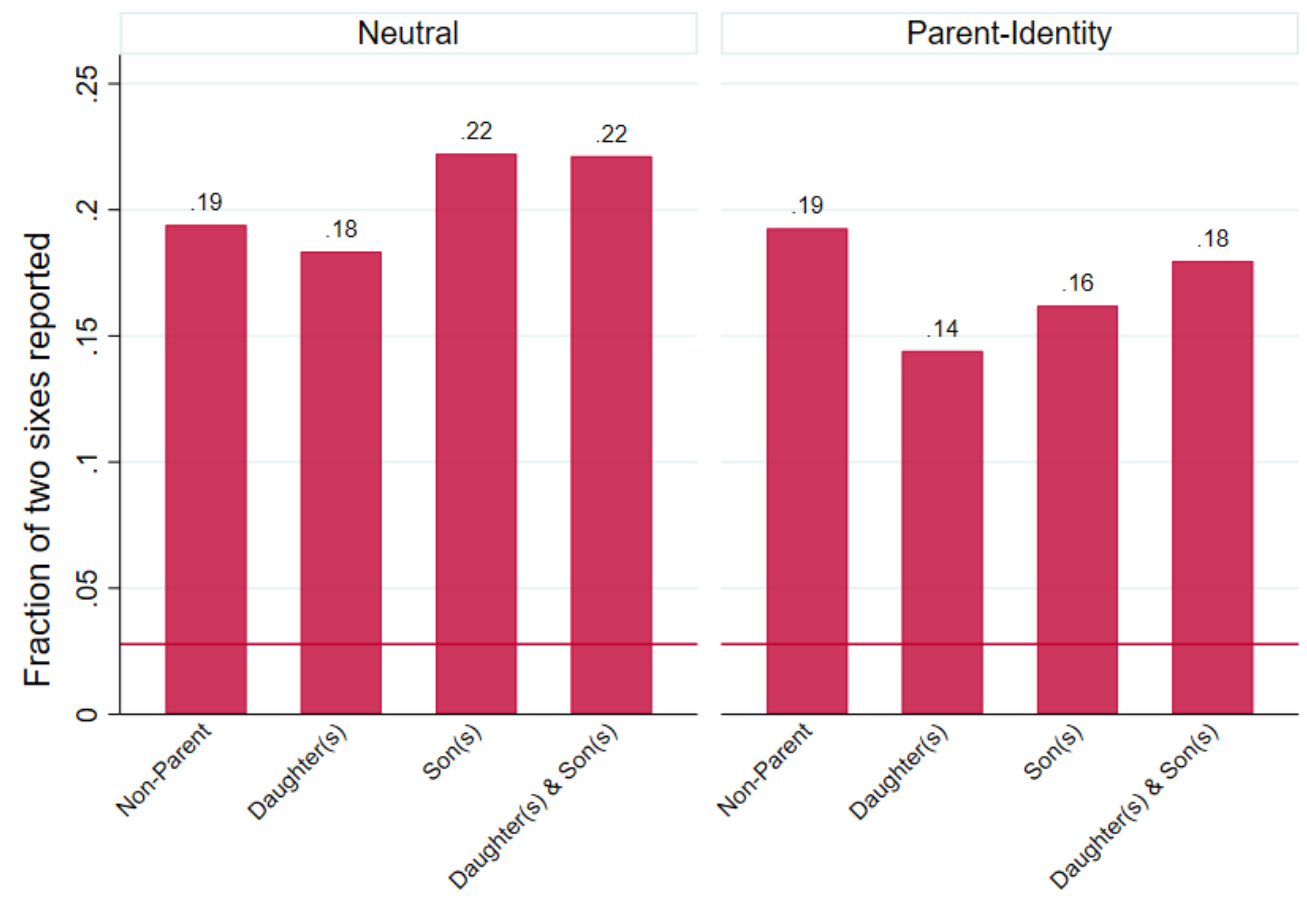

Fig. 3. Fraction of reported two sixes by non-parents, parents of daughter(s), son(s), and daughter(s) and son(s)

Note: The horizontal line highlights the expected fraction of two sixes reported, if the participants are truthful.

In the next step, we test whether the gender of the child affects lying behavior. We distinguish between non-parents, parents of daughter(s), of son(s) and of both daughter(s) and son(s). In line with the aggregate null-results, non-parents, parents of daughter(s), of son(s) and of both daughter(s) and son(s) do not lie significantly differently (19.33\%, 16.30\%, $19.06 \%$, and $20.13 \%$, respectively; $p>0.1$, Chi-squared tests). Figure 3 displays reporting of two sixes in "Neutral" and "Parent-Identity" treatments, by the four groups of participants. While parents with daughters lie the least in each treatment, none of the effects are significant ( $p>0.1$, Chi-squared tests). 


\section{Probit analyses}

In Table 1, we present Probit regression analysis for the effects of the parenthood and treatment on cheating. The dependent variable is a proxy for cheating, which equals to one if a participant reports two sixes, and zero otherwise. The results from Probit regressions show no statistically significant parenthood or treatment effects. The previously found significant effect of the "Parent-Identity" treatment on parent's lying behavior is only marginally significant in the Probit specification, which controls for age and gender. That is, the support for Hypothesis 2 is rather weak and one should treat the result with caution.

Table 1. Probit regression models for lying.

\begin{tabular}{|c|c|c|c|c|c|}
\hline & \multicolumn{5}{|c|}{ Double-six $=1$, Other $=0$} \\
\hline & $\begin{array}{l}\text { Whole } \\
\text { sample }\end{array}$ & $\begin{array}{l}\text { Neutral } \\
\text { treatment }\end{array}$ & $\begin{array}{c}\text { Parent- } \\
\text { identity } \\
\text { treatment }\end{array}$ & Non-parents & Parents \\
\hline & (1) & (2) & (3) & (4) & (5) \\
\hline Parent & $\begin{array}{c}0.019 \\
(0.020)\end{array}$ & $\begin{array}{l}0.049 * \\
(0.028)\end{array}$ & $\begin{array}{l}-0.010 \\
(0.027)\end{array}$ & & \\
\hline $\begin{array}{l}\text { Parent- } \\
\text { Identity }\end{array}$ & $\begin{array}{l}-0.022 \\
(0.018)\end{array}$ & & & $\begin{array}{l}-0.0008 \\
(0.0253)\end{array}$ & $\begin{array}{l}-0.041^{*} \\
(0.024)\end{array}$ \\
\hline Male & $\begin{array}{c}0.093 * * * \\
(0.018)\end{array}$ & $\begin{array}{c}0.094 * * * \\
(0.025)\end{array}$ & $\begin{array}{c}0.092 * * * \\
(0.0001)\end{array}$ & $\begin{array}{c}0.0748 * * \\
(0.0253)\end{array}$ & $\begin{array}{c}0.105 * * * \\
(0.024)\end{array}$ \\
\hline $\begin{array}{l}\text { Age } \\
\text { (logged) }\end{array}$ & $\begin{array}{c}-0.002 * * \\
(0.001)\end{array}$ & $\begin{array}{l}-0.004 * \\
(0.002)\end{array}$ & $\begin{array}{l}-0.0015 \\
(0.0012)\end{array}$ & $\begin{array}{l}-0.0026 \\
(0.0017)\end{array}$ & $\begin{array}{l}-0.002 * \\
(0.001)\end{array}$ \\
\hline $\begin{array}{l}\text { Number of } \\
\text { observations }\end{array}$ & 1978 & 990 & 988 & 962 & 1016 \\
\hline $\begin{array}{l}\mathrm{R}^{2} \\
\text { Nagelkerke }\end{array}$ & 0.033 & 0.033 & 0.029 & 0.019 & 0.046 \\
\hline
\end{tabular}

Notes: The models are Probit specifications with the fraction of reporting of two sixes as the dependent variable. Coefficients are marginal effects from Probit models. *, ** and *** denote significance at the $10 \%, 5 \%$ and $1 \%$ level, respectively. Parent, Parent-Identity, and Male are binary variables equal to one, if the participant is a parent, is in the Parent-Identity treatment, or is a male, respectively. Participants who identified their gender as "other" are not included in these analyses. 
Furthermore, regressions also show that in the "Neutral" treatment, parents lie marginally significantly more; no effect was found using the previously reported nonparametric tests. Finally, Probit regressions confirm that males lie highly significantly more than females, and show that lying marginally significantly decreases with age.

\section{Discussion}

Although the economics literature has extensively studied lying, many questions regarding lying behavior remain unanswered. In this paper, we test the effect of parenthood on cheating. Overall, we find that parenthood does not lead to less cheating. However, parents who are reminded of their children cheat slightly less than parents who receive no reminder. Houser et al. (2016) find that parents cheat less when they are observed by their children than when they are not observed. Our experiment indicates that it might be enough to remind the parents of their children to make them cheat less.

Even though parenthood vitally changes people's lives, there has not been much research on the effects of parenthood on decision making. Future studies of parenthood's effects on cheating behavior could extend the literature by using paradigms that can identify dishonesty on the individual level, and other alternative paradigms to ours, which identify cheating on the group level. Finally, it would be important to see how parenthood affects decision making outside of cheating and risk-taking domains. 


\section{References}

Abeler, J., Becker, A., \& Falk, A. (2014). Representative evidence on lying costs. Journal of Public Economics, 113, 96-104. https://doi.org/10.1016/j.jpubeco.2014.01.005

Abeler, J., Nosenzo, D., \& Raymond, C. (2019). Preferences for Truth-Telling. Econometrica, 87(4), 1115-1153. https://doi.org/10.3982/ECTA14673

Becker, G. S. (1968). Crime and Punishment: An Economic Approach. Journal of Political Economy, 76(2), 169-217.

Boonmanunt, S., Kajackaite, A., \& Meier, S. (2020). Does poverty negate the impact of social norms on cheating? Games and Economic Behavior, 124, 569-578.

https://doi.org/10.1016/j.geb.2020.09.009

Calder-Wang, S., \& Gompers, P. A. (2021). And the children shall lead: Gender diversity and performance in venture capital. Journal of Financial Economics, (in press). https://doi.org/10.1016/j.jfineco.2020.06.026

Capraro, V. (2018). Gender differences in lying in sender-receiver games: A meta-analysis. Judgment and Decision Making, 13(4), 345-355.

Cohn, A., Fehr, E., \& Maréchal, M. A. (2014). Business culture and dishonesty in the banking industry. Nature, 516(7529), 86-89. https://doi.org/10.1038/nature13977

Cohn, A., Maréchal, M. A., \& Noll, T. (2015). Bad Boys: How Criminal Identity Salience Affects Rule Violation. The Review of Economic Studies, 82(4), 1289-1308. https://doi.org/10.1093/restud/rdv025

Cronqvist, H., \& Yu, F. (2017). Shaped by their daughters: Executives, female socialization, and corporate social responsibility. Journal of Financial Economics, 126(3), 543-562. https://doi.org/10.1016/j.jfineco.2017.09.003 
Dahl, M. S., Dezső, C. L., \& Ross, D. G. (2012). Fatherhood and Managerial Style: How a Male CEO's Children Affect the Wages of His Employees. Administrative Science Quarterly, 57(4), 669-693. https://doi.org/10.1177/0001839212466521

Dasgupta, A., Ha, L., Jonnalagadda, S., Schmeiser, S., \& Youngerman, H. (2018). The daughter effect: Do CEOs with daughters hire more women to their board? Applied Economics Letters, 25(13), 891-894. https://doi.org/10.1080/13504851.2017.1380283

Dreber, A., \& Johannesson, M. (2008). Gender differences in deception. Economics Letters, 99(1), 197-199. https://doi.org/10.1016/j.econlet.2007.06.027

Fischbacher, U., \& Föllmi-Heusi, F. (2013). Lies in Disguise-An Experimental Study on Cheating. Journal of the European Economic Association, 11(3), 525-547. https://doi.org/10.1111/jeea.12014

Gächter, S., \& Schulz, J. F. (2016). Intrinsic honesty and the prevalence of rule violations across societies. Nature, 531(7595), 496-499. https://doi.org/10.1038/nature17160

Gneezy, U. (2005). Deception: The Role of Consequences. American Economic Review, 95(1), 384-394. https://doi.org/10.1257/0002828053828662

Gneezy, U., Kajackaite, A., \& Sobel, J. (2018). Lying Aversion and the Size of the Lie. American Economic Review, 108(2), 419-453. https://doi.org/10.1257/aer.20161553

Houser, D., List, J. A., Piovesan, M., Samek, A., \& Winter, J. (2016). Dishonesty: From parents to children. European Economic Review, 82, 242-254. https://doi.org/10.1016/j.euroecorev.2015.11.003

Jacobsen, C., Fosgaard, T. R., \& Pascual-Ezama, D. (2018). Why Do We Lie? A Practical Guide to the Dishonesty Literature. Journal of Economic Surveys, 32(2), 357-387. https://doi.org/10.1111/joes.12204

Kajackaite, A., \& Gneezy, U. (2017). Incentives and cheating. Games and Economic Behavior, 102, 433-444. https://doi.org/10.1016/j.geb.2017.01.015 
Mauro, P. (1995). Corruption and Growth. The Quarterly Journal of Economics, 110(3), 681712. https://doi.org/10.2307/2946696

Mazar, N., Amir, O., \& Ariely, D. (2008). The Dishonesty of Honest People: A Theory of Self-Concept Maintenance. Journal of Marketing Research, 45(6), 633-644. https://doi.org/10.1509/jmkr.45.6.633

Niszczota, P., \& Białek, M. (2020). The effect of gender and parenting daughters on judgments of morally controversial companies. PsyArXiv. https://doi.org/10.31234/osf.io/ukh5c

Palan, S., \& Schitter, C. (2018). Prolific.ac-A subject pool for online experiments. Journal of Behavioral and Experimental Finance, 17, 22-27. https://doi.org/10.1016/j.jbef.2017.12.004

Pogrebna, G., Oswald, A. J., \& Haig, D. (2018). Female babies and risk-aversion: Causal evidence from hospital wards. Journal of Health Economics, 58, 10-17. https://doi.org/10.1016/j.jhealeco.2017.12.006

Shalvi, S., Dana, J., Handgraaf, M. J. J., \& De Dreu, C. K. W. (2011). Justified ethicality: Observing desired counterfactuals modifies ethical perceptions and behavior. Organizational Behavior and Human Decision Processes, 115(2), 181-190. https://doi.org/10.1016/j.obhdp.2011.02.001

Smetana, J. G. (1999). The Role of Parents in Moral Development: A social domain analysis. Journal of Moral Education, 28(3), 311-321. https://doi.org/10.1080/030572499103106

Warner, R. L. (1991). Does the Sex of Your Children Matter? Support for Feminism among Women and Men in the United States and Canada. Journal of Marriage and Family, 53(4), 1051-1056. https://doi.org/10.2307/353008 
Washington, E. L. (2008). Female Socialization: How Daughters Affect Their Legislator Fathers. American Economic Review, 98(1), 311-332.

https://doi.org/10.1257/aer.98.1.311 


\section{Appendix \\ Lying (non-)parents: Being a parent does not reduce dishonesty}

\section{Instructions}

[for the "Parent-Identity" treatment; in the "Neutral" treatment, 'Demographics' section was presented after 'Reporting' section]

\section{Introduction}

This experiment is conducted by researchers Agne Kajackaite (agne.kajackaite@wzb.eu) and Paweł Niszczota (pawel.niszczota@ue.poznan.pl). If you have any concerns regarding the study, do not hesitate to contact the experimenters. The experimental procedures will be explained to you before the start of the experiment. During the experiment you will face a task and your responses will be recorded by us. The data recorded in the experiment do not allow any inference on the participation respectively the responses of individual persons. Correspondingly, the analysis and presentation of all results of this experiment will be anonymized. The anonymous research data will be archived and will possibly be made available to other scientists for further use. Participation in today's experiment is of course entirely voluntary. There will be no disadvantages for you if you decide not to participate. You have the possibility to exit an experiment at any time. We want to ask for your consent to participate in the experiment and to the implied processing of data. Your consent is the legal basis for the processing of data.

If you understand all of the issues and agree to participate in the study, check the consent box and click "Next".

\section{Demographics}

Prior to the task, we'd like to ask you a few demographic questions.

What is your age (in years)?

What is your gender?

How many children do you have? This includes all biological and adopted children, as well as cases where you are step-parent or foster-parent.

\section{Children [only visible for participants with children]}

What is the age of your children (in years)?

Please select the biological sex of each of your children and select if they are your biological children, step children, foster children or adopted children.

For your non-biological children, please state how old they were (in years), when you started being their parent (i.e., adopted them, became their step-parent, or became their foster-parent).

Given that your oldest children have the same age, please state what is the sex of your firstborn child. [only visible for participants whose oldest children had the same age] 


\section{Introduction to task}

Thank you for providing your demographic information. Now, comes the task. For participating in this task you will receive 30 pence $(0.30 \mathrm{GBP})$. Additionally, you might get a bonus from the task described below. Your task will be to roll two dice. You can do this by yourself, if you have two six-sided dice. If not, you can virtually roll two dice by opening a webpage that rolls two virtual dice whenever it is accessed. Therefore, it can be any combination of two numbers between 1 and 6 . If you roll two sixes, you will see the following:

\section{Dice Roller}

You rolled 2 dice:

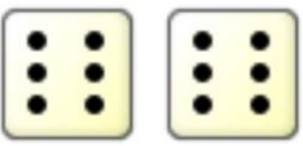

It is important to point out that we will not know what combination of numbers you rolled. Therefore, you will be asked to input these numbers by yourself.

\section{Information on incentives}

If you roll two sixes, you will receive a bonus of 70 pence $(0.70 \mathrm{GBP})$. If you roll any other combinations of numbers, you will not receive a bonus.

\section{Die-rolling}

As mentioned, you can roll your own two six-sided dice, or the virtual dice. The link for the virtual dice is shown below (copy it and enter it in a new browser window).

https://www.random.org/dice/?num=2

You will report what you rolled on the next page.

\section{Reporting}

Please select what you rolled on the first dice [1-6, selected from dropdown list].

Please select what you rolled on the second dice [1-6, selected from dropdown list]. 